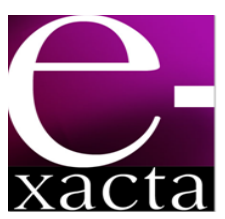

ISSN: 1984-3151

\section{SELEÇÃo dE AMOSTRAS DE ASPERGILLUS SP ISOLADAS DA CAATINGA DE PERNAMBUCO E PRODUÇÃO DE ÁCIDO CÍTRICO POR FERMENTAÇÃO SUBMERSA}

\author{
SELECTION OF SAMPLES ISOLATED ASPERGILLUS SP ISOLATED FROM \\ CAATINGA IN PERNAMBUCO AND PRODUCTION CITRIC ACID FROM \\ SUBMERGED FERMENTATION
}

1 Mestranda em Desenvolvimento de Processos Ambientais, Universidade Católica de Pernambuco, Recife, Pernambuco marciamuniz8@yahoo.com.br

2 Mestre em Desenvolvimento de Processos Ambientais, Universidade Católica de Pernambuco, Recife, Pernambuco brindizeflima@hotmail.com

3 Doutora em Microbiologia Núcleo de Pesquisas em Ciências Ambientais e Biotecnologia (NPCIAMB), Universidade Católica de Pernambuco, Recife, Pernambuco. takaki@unicap.br

4 Doutor em Biotecnologia. Núcleo de Pesquisas em Ciências Ambientais e Biotecnologia (NPCIAMB), Universidade Católica de Pernambuco, Recife, Pernambuco. calves@unicap.br.

Recebido em: 09/09/2014 - Aprovado em: 20/11/2014 - Disponibilizado em: 30/11/2014

RESUMO: O isolamento de novas espécies microbianas em regiões como a Caatinga nordestina tem direcionado novos estudos para a identificação de novas espécies e gêneros microbianos, realização de ensaios biotecnológicos voltados para produção de metabólitos de alto valor agregado. O ácido cítrico é um ácido orgânico comum de quase todos os seres vivos, presente naturalmente em frutas cítricas e apresenta vasta aplicabilidade comercial. Sua produção via micro-organismos é realizada por espécies capazes de converter carboidratos em ácido cítrico, cuja produção é fortemente influenciada pela natureza dos substratos presentes nos meios de fermentação, pois alguns micronutrientes são de extrema importância para a fixação biológica, transformando-se em co-fatores na incorporação de nitrogênio e ocasionando uma melhor produção do bioproduto. $O$ gênero Aspergillus tem se destacado como um bom produtor de ácido cítrico e de outros metabólitos de interesse biotecnológico. Foram realizados estudos de seleção de três amostras de Aspergillus sp isoladas da Caatinga do Estado de Pernambuco, denominadas de SIS 09, 10 e 16 para produção de ácido cítrico em meio sólido e produção de ácido cítrico através de fermentação submersa com a melhor amostra selecionada. Foram testados três meios com diferentes composições. Os experimentos foram realizados em shaker orbital a $28^{\circ} \mathrm{C}, 150 \mathrm{rpm}$, durante 144 horas. Foram coletadas amostras a cada 24 horas para determinações da presença de $A C, p H e$ açúcares redutores totais. Os resultados obtidos evidenciaram que, nos ensaios de seleção de produção de ácido cítrico em meio sólido, a amostra SIS 09 apresentou a formação do maior halo característico obtido de $3,0 \mathrm{~cm}$. Nos ensaios de produção através de fermentação submersa, o meio denominado $M_{1}$ apresentou uma produção de ácido cítrico de 3,05 g/L, pH final de 5,0. A seleção de novos micro-organismos produtores de moléculas potencialmente ativas induz a realização de novos estudos biotecnológicos para melhorarem as condições de produção dos bioprodutos desejados.

PalaVRas-ChaVe: Seleção de meios. Aspergillus. Ácido cítrico.

ABSTRACT: The isolation of new microbial species, especially in regions not yet explored, such as the northeastern Caatinga, has directed new studies for the identification of new microbial species and genera, conducting assays 
involving biotechnological production of metabolites with high added value. Citric acid is a common organic acid in almost all living beings, naturally present in citrus fruits and has extensive commercial applicability. Production via micro-organisms is performed by able to convert carbohydrates into citric acid species, whose production is strongly influenced by the nature of the substrates in fermentation media, as some micronutrients are of extreme importance for the biological fixation, becoming cofactors in the nitrogen incorporation, and resulting improved production of citric acid. The Aspergillus genus has emerged as a good producer of citric acid and other metabolites of biotechnological interest. Studies of selection of three samples isolated from Aspergillus sp from Caatinga region of Pernambuco, denominated SIS 09, 10 and 16 for production of citric acid on solid medium and production of citric acid through submerged fermentation. The best sample was selected fermentation were performed. Three media with different compositions were tested. The experiments were performed on an orbital shaker at $28{ }^{\circ} \mathrm{C}, 150 \mathrm{rpm}$ for 144 hours. Samples were collected every 24 hours for determination of the presence of citric, $\mathrm{pH}$ and total reducing sugars. The results showed that for tests of selection of citric acid production on solid medium, the SIS 09 sample showed the formation of higher characteristic halo, $3.0 \mathrm{~cm}$, respectively. Already in production by submerged fermentation, the medium denominated $\mathrm{M} 1$, which had a production of CA $3.05 \mathrm{~g} / \mathrm{L}$, final $\mathrm{pH}$ of 5.0. The selection of new microorganisms producing potentially active molecules produced new studies biotechnology to improve the conditions of production of desired bioproducts.

KEYWORDS: Media selection. Aspergillus. Citric acid.

\section{INTRODUÇÃO}

A diversidade microbiana mundial é considerada bastante extensa, apesar dos inúmeros estudos taxonômicos realizados para identificação e classificação de novas espécies microbianas existentes por diferentes técnicas. A diversidade das espécies está associada diretamente à opulência e à sua distribuição do número de indivíduos entre essas espécies na natureza sob as diferentes formas existentes no ar, no solo e na água (ZILLI et al., 2003; DIONISI; LOZADA; OLIVEIRA, 2012; VALENCIA; CHAMBERGO, 2013).

A utilização biotecnológica de micro-organismos isolados de ambientes diversos, principalmente aqueles pouco estudados, tem sido alvo de inúmeras pesquisas biotecnológicas sobre a diversidade microbiana, no sentido de isolar, caracterizar e produzir biomoléculas com elevado potencial biotecnológico, aumentando assim os benefícios econômicos e estratégicos relacionados com a descoberta de novos micro-organismos potencialmente exploráveis nos diferentes processos biotecnológicos (STEVEN et al., 2006; SANTOS et al., 2009; NELSON; WEAR, 2014).
A Caatinga é um ecossistema do sertão nordestino que se situa na maior parte dos estados do Piauí, Ceará, Rio Grande do Norte, Paraíba, Pernambuco, Alagoas, Sergipe, Bahia e uma parte do nordeste de Minas Gerais, localizada no vale do Jequitinhonha. Estende-se por cerca de $735.000 \mathrm{Km}^{2}$, sendo limitada a leste e a oeste pelas florestas Atlântica e Amazônica, respectivamente, e ao sul pelo Cerrado. Apresenta um clima semi-árido, quente e com baixos índices pluviométricos, baixa umidade relativa do ar e altas temperaturas durante quase todo o ano (SILVA et al., 2004; LEAL et al., 2005; PINHEIRO; COSTA; ARAÚJO, 2013; COSTA et al.; 2014).

$\mathrm{O}$ ácido cítrico ou citrato de hidrogênio $\left(\mathrm{C}_{6} \mathrm{H}_{8} \mathrm{O}_{7} \cdot \mathrm{H}_{2} \mathrm{O}\right)$ é um ácido tricarboxílico orgânico fraco, amplamente utilizado na indústria alimentícia como conservante natural, acidulante, antioxidante e estabilizador. Após processos de purificação, é incolor e solúvel em água, apresenta peso molecular de $210,14 \mathrm{~g} / \mathrm{mol}$, sendo um metabólito comum de plantas e animais e está presente em diversos sucos de frutas, frutas cítricas e abacaxi (SOCCOL et al., 2006; ANGUMEENAL, VENKAPPAYYA, 2013; ESWARAPPA, FOX, 2013).

Os processos fermentativos utilizados para produção do ácido cítrico industrial podem ser realizados de três maneiras diferentes: através de fermentação 
submersa (o mais utilizado), fermentação de superfície e por fermentação em estado sólido (PAUL; PRIEDE; THOMAS, 1999; KUMAR et al., 2003; DHILLON et al., 2013).

O ácido cítrico é um dos produtos de fermentação mais produzidos no mundo (GREWAL; KALRA, 1995; BEROVIC; LEGISA, 2007; SAUER et al. 2007; MAX et al., 2010; DHILLON et al., 2011; LARBA et al. 2013; ALI; HAQ, 2014), principalmente através da fermentação submersa, utilizando meios de produção à base de sacarose ou amido, e também utilizando resíduos agroindustriais (PAUL; PRIEDE; THOMAS, 1999; DHILLON et al., 2011; PANDEY et al., 2013; AMENAGHAWON et al., 2013; AMENAGHAWON; OSAZUWA; OKIEIMEN, 2014; ALONSO; RENDUELES; DÍAZ, 2014).

O gênero Aspergillus tem se destacado como um dos melhores produtores de diversos metabólitos secundários de interesse industrial e ambiental (YIGITOGLU, 1992; DEMAIN, 1999; SCHUSTER et al., 2002; NIELSEN et al., 2009; MAJUMDER et al., 2010; BRAKHAGE, SCHROECKH, 2011; FRISVADI et al., 2011; ALJUBOORI et al. 2013; PASIN et al., 2014), devido à sua uma elevada taxa de crescimento e de termotolerância, o que tem favorecido a execução de inúmeros estudos de seleção e produção de bioprodutos de alto valor agregado (DRIOUCH; SOMMER; WITTMANN, 2010; LIMA et al., 2014; NASCIMENTO et al., 2014).

Este trabalho teve como objetivos a seleção de amostras de Aspergillus sp isoladas da Caatinga de Pernambuco com potencial de produção de ácido cítrico e a seleção de meios de produção de ácido cítrico através de fermentação submersa.

\section{MATERIAL E MÉTODOS}

\subsection{MICRO-ORGANISMOS}

Foram utilizadas culturas de fungos filamentosos do gênero Aspergillus $\mathrm{sp}$ isolados da Caatinga de Pernambuco, denominados de SIS 09, 10 e 16, previamente catalogados no Banco de Culturas da Universidade Católica de Pernambuco (UNICAP), localizado no Núcleo de Pesquisas em Ciências Ambientais e Biotecnologia (NPCIAMB). As culturas foram mantidas em meio Ágar Sabouraud Dextrose (ASD), com a seguinte composição: dextrose (40 g/L), peptona (10 g/L), ágar (20 g/L), água destilada 1000 $\mathrm{mL}$ e $\mathrm{pH} 7,0$. As amostras testadas foram aclimatadas em meios de manutenção contendo $2 \mathrm{~g} / \mathrm{L}$ de ácido cítrico.

\subsection{Seleção de amostras produtoras de ÁCIDO CÍTRICO EM MEIO SÓLIDO}

A seleção foi realizada através da metodologia descrita por Foster (1949). O meio utilizado apresentava a seguinte composição: $5 \mathrm{~g} / \mathrm{L}$ de glicose; $1 \mathrm{~g} / \mathrm{L}$ de peptona; $1 \mathrm{~g} / \mathrm{L}$ de $\mathrm{KH}_{2} \mathrm{PO}_{4} ; 0,5 \mathrm{~g} / \mathrm{L}$ de $\mathrm{MgSO}_{4}$; $15 \mathrm{~g} / \mathrm{L}$ de Ágar e $65 \mathrm{~mL} / \mathrm{L}$ de solução de Verde de Bromocresol $(0,5 \mathrm{~g}$ Verde de Bromocresol em $7 \mathrm{~mL}$ de $\mathrm{NaOH} 0,1 \mathrm{~N}$ ). $\mathrm{O} \mathrm{pH}$ foi ajustado para 4,5. As placas foram incubadas durante 96 horas, $28{ }^{\circ} \mathrm{C}$ com acompanhamento diário. $\mathrm{O}$ aparecimento de um halo amarelo brilhante evidenciava a produção de ácido cítrico no meio testado. Todos os ensaios foram realizados em triplicata.

\subsection{Seleção de meios de PROduÇão de Ácido CÍTRICO EM FERMENTAÇÃO SUBMERSA}

Após a seleção da melhor amostra produtora de ácido cítrico, foram selecionados e testados meios de produção de AC através de fermentação submersa, 
durante 144 horas, $28^{\circ} \mathrm{C}, 150 \mathrm{rpm}$, com amostras coletadas a cada 24 horas..

Meio $1\left(\mathrm{M}_{1}\right)-\mathrm{MgSO}_{4} .7 \mathrm{H}_{2} \mathrm{O}, 0,23 \mathrm{~g} / \mathrm{L} ; \mathrm{KH}_{2} \mathrm{PO}_{4}, 1,0 \mathrm{~g} / \mathrm{L}$; $\mathrm{NH}_{4} \mathrm{NO}_{3}, \quad 1,0 \mathrm{~g} / \mathrm{L}$; sacarose, $50 \mathrm{~g} / \mathrm{L}$; uréia, $2,5 \mathrm{~g} / \mathrm{L}$; peptona, 2,5g/L; $\left(\mathrm{NH}_{4}\right)_{2} \mathrm{SO}_{4}, 2,5 \mathrm{~g} / \mathrm{L}$;

Meio $2\left(\mathrm{M}_{2}\right)-\mathrm{KH}_{2} \mathrm{PO}_{4}, 5,0 \mathrm{~g} / \mathrm{L}$; citrato trissódico, 5,0g/L; $\mathrm{NH}_{4} \mathrm{NO}_{3}, 2,0 \mathrm{~g} / \mathrm{L} ; \quad\left(\mathrm{NH}_{4}\right)_{2} \mathrm{SO}_{4}, 4,0 \mathrm{~g} / \mathrm{L} ; \mathrm{MgSO}_{4} .7 \mathrm{H}_{2} \mathrm{O}$, $0,2 \mathrm{~g} / \mathrm{L}$; peptona, $1,0 \mathrm{~g} / \mathrm{L}$; glicose, $0,2 \mathrm{~g} / \mathrm{L}$; extrato de levedura, 2,0g/L;

Meio 3 ( $\mathbf{M}_{3}$ )- $\mathrm{NaNO}_{3}, 6,0 \mathrm{~g} / \mathrm{L} ; \mathrm{KH}_{2} \mathrm{PO}_{4}, 1,5 \mathrm{~g} / \mathrm{L} ; \mathrm{KCl}$, 0,5g/L; $\mathrm{MgSO}_{4} .7 \mathrm{H}_{2} \mathrm{O}, 0,5 \mathrm{~g} / \mathrm{L} ; \mathrm{FeSO}_{4}, 0,01 \mathrm{~g} / \mathrm{L} ; \mathrm{ZnSO}_{4}$, 0,01g/L; glicose, 10g/L; peptona, 2,0g/L; extrato de levedura, 2,0g/L; tiamina, $0,3 \mathrm{~g}$.

\subsection{DETERMINAÇÃO DO PH}

Todas as amostras coletadas foram submetidas a leituras no potenciômetro para leitura do $\mathrm{pH}$.

\subsection{DeterminaçÃo dA PROdUÇÃo DE ÁCIDO Cítrico}

Para a determinação do ácido cítrico produzido através de fermentação submersa, utilizou-se a metodologia de Saffran e Denstedt (1948), em que a quantidade de ácido cítrico é identificada através da formação de uma cor amarela, pela reação entre o ácido tricloroacético (TCA) com piridina e o anidrido acético.

A reação foi realizada através da introdução de $1,0 \mathrm{~mL}$ das amostras coletadas ao longo do processo fermentativo em um recipiente contendo $8,0 \mathrm{~mL}$ de anidrido acético. Em seguida, os frascos foram aquecidos em banho-maria durante 10 minutos, até o aquecimento das misturas. Após o aquecimento, acrescentou-se $1,0 \mathrm{~mL}$ de piridina em cada tubo a ser testado. Os tubos foram agitados e retornados ao banho-maria por mais 40 minutos.
Durante esse período de aquecimento, as amostras assumiram uma coloração que pode variar do amarelo ao marrom escuro, dependendo da concentração de ácido cítrico presente em cada amostra. As amostras foram retiradas do banho-maria para um banho de gelo durante 5 minutos. Sua leitura foi realizada em espectrofotômetro em um comprimento de onda de $400 \mathrm{~nm}$.

Para o branco, foi utilizado $1,0 \mathrm{~mL}$ de TCA (15\%), e adicionado $8,0 \mathrm{~mL}$ de anidrido acético, seguido de banho-maria por 10 minutos a $60^{\circ} \mathrm{C}$. Em seguida, foi adicionado $1,0 \mathrm{~mL}$ de piridina, tendo 0 material retornado ao banho-maria por mais 40 minutos, seguido de banho de gelo durante 5 minutos.

A curva padrão foi construída utilizando-se $1 \mathrm{~mL}$ de solução de ácido cítrico (4g de ácido cítrico em 100mL de TCA a 15\%). As leituras foram realizadas em espectrofotômetro a um comprimento de onda de 400 $\mathrm{nm}$.

\subsection{DETERMINAÇÃo dOS AÇÚCARES REDUTORES TOTAIS}

Os açúcares redutores totais das amostras coletadas foram determinados através da metodologia de Miller (1959), que utiliza o DNS (ácido dinitro-salić́lico), o qual oxida o grupo carbonila presente na solução.

Foram utilizadas alíquotas de $0,5 \mathrm{~mL}$ das amostras coletadas no processo de fermentação, e colocadas em frascos contendo $0,5 \mathrm{~mL}$ da solução do reagente DNS. Em seguida, as amostras foram aquecidas em banho-maria durante 5 minutos, em temperatura de ebulição.

Após resfriamento em água corrente, foram adicionados $5 \mathrm{~mL}$ de água destilada em cada amostra a ser lida. A leitura da absorbância foi realizada em espectrofotômetro a um comprimento de $540 \mathrm{~nm}$. As leituras obtidas foram correlacionadas com a 
concentração de açúcar redutor (AR) utilizando-se uma curva padrão de glicose.

\section{Resultados e discussão}

Foram realizados ensaios de isolamento e identificação de microrganismos oriundos de amostras de solo da Caatinga do estado de Pernambuco, no município de Serra Talhada. Diversos gêneros de fungos filamentosos foram isolados e identificados, principalmente o gênero Aspergillus, considerado pela literatura um dos gêneros mais promissores de produção de biomoléculas potencialmente ativas.

Grewal e Kalra (1995), Vandenberghe et al. (1999), Angumeenal e Venkappayya (2013), assim como Thevenieau e Nicaud (2013) descreveram que, ao longo das últimas décadas, um elevado número de micro-organismos isolados de ambientes diversos têm sido testados para avaliação do potencial biotecnológico para produção de ácido cítrico, incluindo principalmente fungos filamentosos, leveduras e bactérias.

Soares Costa et al. (2014) descrevem que fungos filamentosos do gênero Aspergillus, pricipalmente da espécie niger, têm sido usados para produção comercial de AC. As principais vantagens da utilização desses organismos são: (i) a sua facilidade de manuseio; (ii) a sua capacidade para fermentar uma ampla variedade de matérias-primas baratas utilizadas na formulação dos meios de produção e (iii) elevados rendimentos alcançados.

Foram realizados ensaios de detecção da produção de ácido cítrico em meio sólido, através da metodologia descrita por Foster (1949), na qual três amostras de Aspergillus sp isoladas da Caatinga do estado de Pernambuco, denominadas de SIS 09, 10 e 16, foram testadas. Os resultados obtidos estão descritos na Tabela 1.
Tabela 1- Seleção de amostras de Aspergillus sp produtoras de ácido cítrico em meio sólido

\begin{tabular}{c|c|c|c|c}
\hline Amostras & $\begin{array}{c}\mathbf{2 4 h} \\
(\mathbf{c m})\end{array}$ & $\begin{array}{c}48 \mathrm{~h} \\
(\mathbf{c m})\end{array}$ & $\begin{array}{c}\mathbf{7 2 h} \\
(\mathbf{c m})\end{array}$ & $\begin{array}{c}\mathbf{9 6 h} \\
(\mathbf{c m})\end{array}$ \\
\hline SIS 09 & 1,5 & 3,0 & 4,0 & 6,0 \\
SIS 10 & 1,0 & 2,0 & 2,5 & 3,0 \\
SIS 16 & 2,0 & 2,0 & 2,5 & 2,5 \\
\hline
\end{tabular}

Os resultados indicaram que todos os microorganismos testados apresentaram a habilidade em produzir o ácido cítrico, porém a amostra denominada de SIS 09 apresentou o maior halo característico formado, após 96 horas, que foi de $6,0 \mathrm{~cm}$.

As demais amostras testadas (SIS 10 e SIS 16), também produziram ácido cítrico em todo período do ensaio, apresentando a formação de halos característicos de 3,0 e 2,5 cm, respectivamente.

Rodrigues (2006) descreve que cada amostra de micro-organismo do mesmo gênero, isolada em ambientes diversos, pode apresentar particularidades quanto ao tempo de produção, quantidade de AC produzido e adaptação ao meio utilizado.

A produção do ácido cítrico é normalmente realizada através de processos fermentativos, sendo essa a maneira mais econômica de obtenção desse ácido orgânico, pois mais de $90 \%$ da produção mundial desse ácido é obtida por fermentação submersa (KOLICHESKI; SOCCOL, 1995; DASHEN et al., 2013).

Para que a obtenção do ácido cítrico seja considerada viável comercialmente, vários fatores devem ser levados em consideração durante a elaboração das condições operacionais do processo fermentativo a ser realizado, como os constituintes do meio de produção, o pH, a aeração, a temperatura e a seleção do microrganismo produtor (KOLICHESKI; SOCCOL, 1995; PASTORE; HASAN; ZEMPULSKI, 2011; LÓPEZ-GARZÓN; STRAATHOF, 2014). 
Foram realizados ensaios de produção de ácido cítrico, com a amostra selecionada SIS 09 em três diferentes meios de produção com composições químicas variadas, durante 144 horas, $28^{\circ} \mathrm{C}, 150 \mathrm{rpm}$.

Verifica-se que o meio denominado de $\mathrm{M}_{1}$ apresentou o melhor resultado em termos de produção de ácido cítrico, durante as $144 \mathrm{~h}$ de fermentação, apresentando um valor de produção de $8,85 \mathrm{~g} / \mathrm{L}$. A mesma amostra testada no meio $\mathrm{M}_{2}$ obteve $3,19 \mathrm{~g} / \mathrm{L}$ durante o mesmo período de fermentação, enquanto que $\circ \mathrm{M}_{3}$ obteve uma produção de 2,99 g/L (Figura 1).

A formulação de meios de produção de ácido cítrico por fermentação submersa envolve uma série de fatores que podem influenciar diretamente na produção desse ácido orgânico. Angumeenal e Venkappayya (2013) descrevem que a composição dos substratos utilizados no meio de produção de ácido cítrico está relacionada diretamente com a quantidade e a qualidade da fonte de carbono selecionada.

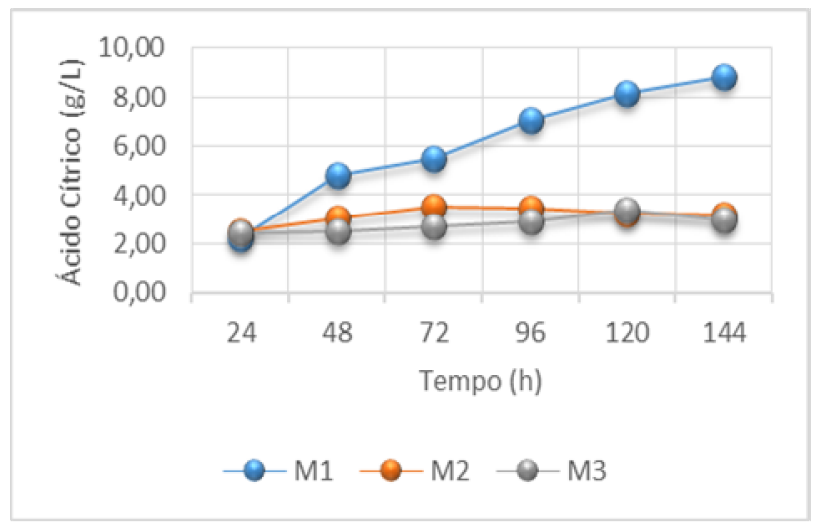

Figura 1 - Produção de ácido cítrico pela amostra SIS 09 por fermentação submersa em diferentes meios

O meio denominado $M_{1}$ apresenta na sua formulação como fonte de carbono a sacarose, um dissacarídeo cuja fórmula molecular é $\mathrm{C}_{12} \mathrm{H}_{22} \mathrm{O}_{11}$, sendo um tipo de glicídio formado por uma molécula de glicose e uma de frutose. Os meios denominados de $M_{2}$ e $M_{3}$ apresentaram em sua composição o monossacarídeo glicose, cuja fórmula molecular é $\mathrm{C}_{6} \mathrm{H}_{12} \mathrm{O}_{6}$, sendo encontrado na natureza sob a forma livre ou combinada. Juntamente com a frutose e a galactose, é o carboidrato fundamental de carboidratos maiores, como sacarose e maltose. Amido e celulose são polímeros de glucose.

Vandenberghe et al. (1999), Dhillon et al. (2010), bem como Angumeennal e Venkappayya (2013) descreveram a necessidade da utilização de fontes de carbono, devido à rápida assimilação dos fungos filamentosos, principalmente o gênero Aspergillus pelas variadas fontes de carbono usualmente utilizadas nas composições dos meios de produção, como a glicose, frutose, sacarose, que geram um elevado rendimento final na produção do ácido cítrico.

Estudos realizados por $\mathrm{Xu}$ et al. (1989), com a amostra denominada B60 de $A$. Niger, utilizando dois dissacarídeos na composição do meio de produção, a maltose e a sacarose, demosntraram ser as melhores fontes de carbono para produção do ácido cítrico, quando comparadas à glicose e à frutose. Alguns açúcares monossacarídeos, como galactose e arabinose, são relatados pela literatura como inibidores da produção de ácido cítrico e devem ser evitados na elaboração dos meios de produção (HOSSAIN; BROOKS; MODDAX, 1985; MADDOX et al., 1985).

Outra característica importante a ser avaliada na produção de ácido cítrico é a concentração da fonte de carbono a ser utilizada na composição do meio de produção. Nos experimentos realizados com a amostra SIS 09, foram utilizadas no meio denominado de $M_{1} 50 \mathrm{~g} / L$ de sacarose, enquanto que nos meios $M_{2}$ e $M_{3}$ foram utilizadas 1 e $10 \mathrm{~g} / \mathrm{L}$, respectivamente.

Shu e Johnson (1948) demonstraram que a taxa de produção do ácido cítrico máxima é obtida com uma concentração de açúcares na faixa de 14 a 22\%, dependendo da composição química do açúcar utilizado. 
Estudos realizados por Anderson et al. (1980) descreveram que a utilização de soluções contendo açúcares com 2, 6 e 10\% dão rendimentos baixos de produção de ácido cítrico, quando comparados a soluções com concentrações de 14, 18 e $20 \%$. Xu et al. (1989) indicaram, através dos resultados obtidos nos experimentos realizados, que a concentração ótima de sacarose utilizada deveria ser em torno de $10-14 \%$.

Pastore et al. (2011) descrevem a necessidade da utilização de fontes de nitrogênio na composição do meio de produção de ácido cítrico, pois, dependendo da espécie do fungo, o nitrogênio pode ser obtido nas formas de nitrato, nitrito, amônia ou nitrogênio orgânico.

$\mathrm{Na}$ formulação dos meios testados para produção do ácido cítrico, foram utilizadas soluções de sais contendo diferentes componentes que apresentavam em sua composição variadas fontes de nitrogênio.

Soccol et al. (2006) citam que a fermentação cítrica submersa requer também uma concentração de fonte de nitrogênio na faixa de 0,1 a $0,4 \mathrm{~g} / \mathrm{L}$, pois uma elevada quantidade de nitrogênio na composição do meio propicia um elevado crescimento fúngico e consequentemente rápido consumo do substrato, diminuindo assim o acúmulo do ácido cítrico no meio de fermentação.

Os estudos realizados na determinação do $\mathrm{pH}$, durante a produção de ácido cítrico utilizando os três diferentes meios de produção, demonstraram que os valores obtidos dos $\mathrm{pH}$ finais apresentaram um aumento significativo quando comparados aos valores iniciais do processo de produção (Tabela 2).

Em todos os experimentos realizados, os valores de $\mathrm{pH}$ dos meios de produção do $\mathrm{AC}$ foram iniciados com valores na faixa de 4,0. Essas condições de acidez no $\mathrm{pH}$ são devido aos fungos filamentosos, principalmente do gênero Aspergillus geralmente realizarem uma boa produção de ácido cítrico, quando se encontram sob condições de estresse, ou seja, $\mathrm{pH}$ ácido no início do processo fermentativo.

Tabela 2 - Variação do pH na produção de ácido cítrico pela amostra SIS 09 em diferentes meios testados

\begin{tabular}{l|l|l|l|l|l|l|l}
\hline $\begin{array}{l}\text { Meios de } \\
\begin{array}{l}\text { Produção } \\
\text { de ácido }\end{array}\end{array}$ & Oh & $\mathbf{2 4 h}$ & $\mathbf{4 8 h}$ & $\mathbf{7 2 h}$ & $\mathbf{9 6 h}$ & $\mathbf{1 2 0 h}$ & $\mathbf{1 4 4 h}$ \\
cítrico & & & & & & & \\
\hline Meio 1 & 4,0 & 4,0 & 4,5 & 4,5 & 4,5 & 4,5 & 5,0 \\
Meio 2 & 4,0 & 4,5 & 6,0 & 6,0 & 6,0 & 6,0 & 6,0 \\
Meio 3 & 4,0 & 4,0 & 4,5 & 5,5 & 6,0 & 6,0 & 6,0 \\
\hline
\end{tabular}

Verificou-se que, nas primeiras 24 horas, não houve uma variação significativa dos valores. Tendo apenas o $\mathrm{M}_{2}$ aumentado para 4,5, os demais meios $\left(\mathrm{M}_{1}\right.$ e $\left.\mathrm{M}_{3}\right)$ permaneceram constantes.

Durante quase todo o processo de produção do ácido cítrico, o meio $M_{1}$ permaneceu com o valor de 4,5, tendo aumentado para 5,0 ao término do processo, ou seja, após 144 horas de produção. Os demais meios testados $M_{2}$ e $M_{3}$, após 144 horas, apresentaram valores de $\mathrm{pH}$ de 6,0 , respectivamente.

Pastore et al. (2011) descrevem que as mudanças de $\mathrm{pH}$ ao longo do processo de produção dependem principalmente do micro-organismo utilizado e dos substratos usados para elaboração da composição dos meios de produção, bem como a utilização de sais de amônio ou ureia para amenizarem a variação brusca de $\mathrm{pH}$ durante as várias etapas do processo fermentativo.

Não existe um consenso na literatura com relação a um pH inicial para a produção de ácido cítrico, ainda que $\circ \mathrm{pH}$ mais favorável ao desenvolvimento dos fungos filamentosos esteja numa faixa que varia entre 5,6 e 7 , pois a maioria dos fungos tolera uma ampla 
variação de $\mathrm{pH}$, entre 1,5 e 11, porém, segundo Del Bianchi et al. (2001), os valores considerados ótimos de $\mathrm{pH}$ devem se encontrar na faixa de valores entre 4 e 6.

Os valores iniciais em ambos os meios testados $\left(M_{1}\right.$, $M_{2}$ e $M_{3}$ ) estiveram na faixa de 4,0 , que favorece o melhor desempenho do fungo filamentoso na produção dos ácidos orgânicos, principalmente o cítrico.

Os valores finais dos experimentos realizados para produção de ácido cítrico se mantiveram dentro da faixa descrita na literatura, em que, após 144 horas de fermentação, o meio $M_{1}$ apresentou valores de 5,0, enquanto que os meios $M_{2}$ e $M_{3}$, valores de 6,0 , respectivamente.

Rodrigues (2006) descreveu que o ideal é se iniciar uma fermentação submersa para produção de ácido cítrico com valores de $\mathrm{pH}$ um pouco elevados, entre a faixa de 5,0 e 6,0, para permitir um bom crescimento dos esporos fúngicos. $\mathrm{E}$, durante o processo fermentativo, a produção de ácidos irá contribuir para a redução gradativa do $\mathrm{pH}$.

Pastore et al. (2011) relataram que a utilização de valores de $\mathrm{pH}$ baixos apresentam como vantagem a inibição da produção de alguns ácidos considerados indesejáveis, como o oxálico e o glucônico.

O consumo dos açúcares redutores totais foi acompanhado nas diferentes composições de meios testados para produção de ácido cítrico (Figura 2). Verifica-se que o consumo da glicose ao longo da fermentação ocorreu de forma regular, porém a amostra SIS 09 conseguiu produzir um maior acúmulo de ácido cítrico no meio $M_{1}$, devido à concentração de sacarose introduzida na composição original do meio.

Os resultados obtidos indicaram que as concentrações iniciais de açúcares nas primeiras 24 horas de produção de ácido cítrico nos meios denominados de $M_{1}, M_{2}$ e $M_{3}$ foram de 166, 0,7 e $35 \mathrm{~g} / \mathrm{L}$, respectivamente. Ao término do processo, após 144 horas, foram obtidos valores de $12,0,5$ e $0,7 \mathrm{~g} / \mathrm{L}$, respectivamente.

Pastore et al (2011) descreveram que o ácido cítrico pode ser acumulado de duas formas: quando vários nutrientes estão presentes em altas concentrações (açúcar, acidez, oxigênio) ou quando estão em níveis abaixo do ótimo (íons metálicos, nitrogênio, fosfato).

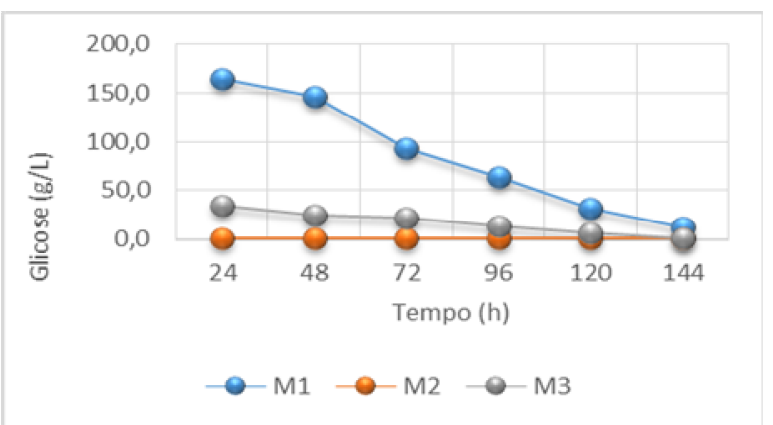

Figura 2 - Determinação do consumo de glicose em diferentes meios testados para produção de AC

Penna (2001) relatou que os diferentes tipos de açúcares introduzidos na composição dos meios de produção são assimilados de forma rápida pelos fungos como fonte de carbono nos processos fermentativos, em que a concentração e tipo de fonte de carbono utilizada são relevantes fatores respostas relacionados ao acúmulo ou não de ácido cítrico. A baixa concentração de açúcar nos meios de produção pode comprometer diretamente a formação de ácido cítrico, facilitando assim o acúmulo de outros ácidos orgânicos, como o oxálico, que também são produzidos no processo fermentativo, mas em menor escala.

Roehr, Kubicek e Kominek (1996) afirmaram que a principal fonte de carbono empregada na formulação de meios de produção de ácido cítrico deve ser a sacarose, seja na forma pura ou na forma de melaços de cana-de-açúcar ou beterraba. Os resultados 
obtidos evidenciam que o meio $M_{1}$ possui sacarose em sua composição.

\section{CONSIDERAÇÕES FINAIS}

A pouca quantidade de informações referentes ao potencial biotecnológico dos micro-organismos oriundos de regiões como a Caatinga do Nordeste brasileiro tem gerado novos estudos referentes ao isolamento, à identificação e à avaliação do potencial biotecnológico, em que novas espécies de microorganismos são identificadas através de estudos taxonômicos envolvendo biologia molecular.

O ácido cítrico é um composto orgânico que apresenta inúmeras aplicações tecnológicas, sendo utilizado em diversos processos industriais, assim considerado um composto de elevado potencial biotecnológico em diversas indústrias, principalmente na de alimentos.

A habilidade da amostra SIS 09 (Aspergillus sp) isolada da Caatinga de Pernambuco foi evidenciada através de estudos envolvendo a seleção em meio sólido e a produção de ácido cítrico em diferentes meios de produção através da fermentação submersa, evidenciando assim um elevado potencial biotecnológico dessa amostra isolada de um ambiente ainda pouco explorado e estudado biotecnologicamente, pois apresenta uma extensa diversidade microbiana conhecida.

\section{AgRADECIMENTOS}

Os autores agradecem ao Projeto SISBIOTA - CNPq e à FACEPE, pelo suporte financeiro para realização desse trabalho, e ao Núcleo de Pesquisas em Ciências Ambientais e Biotecnologia (NPCIAMB) da Universidade Católica de Pernambuco (UNICAP) pela infraestrutura para execução de a toda parte experimental.

\section{REFERÊNCIAS}

ANDERSON, J.G. et al. Use of the disc fermenter to examine production of citric acid by Aspergillus niger. Biotechnol Letters, v.2, p.99-104, 1980.

ALJUBOORI, A. H. R. et al. Production and characterization of a bioflocculant produced by Aspergillus flavus. Bioresource Technology, v.127, p.489-493, 2013.

ALI, S.; HAQ, I. U Process Optimization of citric acid production from Aspergillus niger using fuzzy logic design. Pak. J. Bot, v. 46, n. 3, p.1055-1059, 2014.

ALONSO, S.; RENDUELES, M.; DÍAZ, M. Microbial production of specialty organic acids from renewable and waste materials. Critical Reviews in Biotechnology, p.1-17, 2014.

AMENAGHAWON, N. A. et al. Application of BoxBehnken Design for the optimization of citric acid production from corn starch using Aspergillus niger. British Biotechnology Journal, n.3, v.3, p.236-245, 2013.
AMENAGHAWON, N. A.; OSAZUWA, O. U.; OKIEIMEN, C.O. Dynamic modeling and simulation of citric acid production from dilute acid hydrolysed corn starch using Aspergillus niger. Nigerian Journal of Technology, v.33, n.2, p.222-229, 2014.

ANGUMEENAL, A. R., VENKAPPAYYA, D. An overview of citric acid production. Food Science and Technology, v.50, p.367-370, 2013.

BRAKHAGE, A. A.; SCHROECKH, V. Fungal secondary metabolites- Strategies to activate silent gene clusters. Fungal Genetics and Biology, v.48, n.1, p. 15-22, 2011.

BEROVIC, M.; LEGISA, M.. Citric acid production. Biotechnology Annual Review, v. 13, p. 303-343, 2007.

COSTA, P. A. et al. Changes in soil pore network in response to twenty-three years of irrigation in a tropical semiarid pasture from northeast Brazil. Soil \& Tillage Research, v. 137, p. 23-32, 2014. 
DASHEN, M. M. et al. Screening and improvement of local isolates of Aspergillus niger for citric acid production. Bayero Journal of Pure and Applied Sciences, n.6, n.1, p.105-111, 2013.

DEMAIN, A. L. Pharmaceutically active secondary metabolites of microorganisms. Applied Microbiology and Biotechnology, v.52, n.4, p.455-463, 1999.

DEL BIANCHI, V. L. et al. Fermentação em estado sólido. In: SCHMIDELL, W. et al. (Coords). Biotecnologia industrial, v. 2, 2001.

DHILLON, G. S. et al. Screening of agro-industrial wastes for citric acid bioproduction by Aspergillus niger NRRL 2001 through solid state fermentation. Journal of the Science of Food and Agriculture, v. 93, n. 7, p. 1560-1567, 2013.

DHILLON, G. S. et al. Utilization of different agroindustrial wastes for sustainable bioproduction of citric acid by Aspergillus niger. Biochemical Engineering Journal, v.54, p.83-92, 2011.

DHILLON, G. S. et al. Recent advances in citric acid bio-production and recovery. Food Bioprocess Techol. v.4, n.4, p.505-529, 2011.

DIONISI, H. M.; LOZADA, M.; OLIVEIRA, N. L. Bioprospection of marine microorganisms: biotechnological applications and methods. Revista Argentina de Microbiología, v.44, p. 49-60, 2012.

DRIOUCH, H.; SOMMER, B.; WITTMANN, C. Morphology engineering of Aspergillus niger for improved enzyme production. Biotechnology and Bioengineering, v.105, n.6, p.1058-1068, 2010.

ESWARAPPA, S. M.; FOX, P. L. Citric acid cycle and the origin of MARS. Trends Biochem. Sci. v.38, n.5, p. 222-228, 2013

FOSTER, J. W. Chemical Activities of Fungi. Academic Press, New York, 1949.

FRISVADI, J. C. et al. Fumonisin and Ochratoxin production in industrial Aspergillus niger strains. PLoS One, v. 6, n. 8, p. e23496, 2011

GREWAL, H. S.; KALRA, K. L. Fungal production of citric acid. Biotechnology Advances, v.13, n.2, p. 209-234, 1995.

HOSSAIN, M.; BROOKS, J. D.; MODDAX, I. S. Galactose inhibition of citric production from glucose by Aspergillus niger. Appl. Microbiol. Biotechnol. v. 22, p. 98-102, 1985.

KOLICHESKI, M. B., SOCCOL, C. R. Otimização do meio e condições de cultura na produção de ácido cítrico por fermentação submersa. B. Ceppa, v.13, n.2, 109-118, 1995.

KUMAR, D. et al. Utilisation of fruits wastes for citric acid production by solid state fermentation. Process Biochemistry, v.38, p.1725-1729, 2003.

LARBA, R. et al. Citric acid as an alternative lixiviant for zinc oxide dissolution. Hydrometallurgy, v.134135, p.117-123, 2013.

LEAL, I. R. et al. Mudando o curso da conservação da biodiversidade na caatinga do Nordeste do Brasil. Megadiversidade, v. 1, n. 1, p. 139-146, 2005.

LIMA, B. F. et al. Seleção de meios de produção de lipase por amostras de Aspergillus sp isoladas da Caatinga de Pernambuco. Revista e-xacta, v.7, n.1, p.147-157, 2014.

LÓPEZ-GARZÓN, C. S.; STRAATHOF, A. J. J. Recovery of carboxylic acids produced by fermentation. Biotechnology Advances, v.32, p.873904, 2014.

MADDOX, I. S. et al. Production of citric acid from sugar present in wood hemicellulose using Aspergillus niger and Saccharomycopsis lipolytica. Biotechnology Letters, v. 7, p. 815-818, 1985.

MAJUMDER, L. et al. Citric acid production by Aspergillus niger using molasses and pumpkin as substrates. European Journal of Biological Sciences, n.2, v.1, p. 1-8, 2010.

MAX, B. et al. Biotechnological production of citric acid, Brazilian Journal of Microbiology, v.41, p.862875, 2010.

MILLER, G. L. Use of dinitrosalicylic reagent for determination of reducing sugar. Analytical Chemistry, v.31, p. 426-428, 1959.

NASCIMENTO, K. B. M. et al. Utilização de resíduos agroindustriais para a produção de tanase por Aspergillus sp isolado do solo da Caatinga de Pernambuco, Brasil. Revista e-xacta, v.7, n.1, p.95103, 2014.

NELSON, C. E.; WEAR, E. K. Microbial diversity and the hability of dissolved organic carbon. Proceedings of the National Academy of Sciences, v. 111, n. 20, p. 7166 - 7167, 2014.

NIELSEN, K. F. et al. Review of secondary metabolites and mycotoxins from the Aspergillus niger group. Analytical and Bioanalytical Chemistry, v.395, n.5, p.1225-1242, 2009. 
PANDEY, P. et al. Studies on citric acid production by Aspergillus niger in batch fermentation. Recent Research in Science and Technology, v.5, n.2, p. 66-67, 2013.

PASIN, T. M. et al. Prospecting Filamentous Fungi for Amylase Production: Standardization of Aspergillus japonicus Culture Conditions. British Biotechnology Journal, v.4, n..4, p. 482-498, 2014.

PASTORE, N. S., HASAN, S. M., ZEMPULSKI, D. A. Produção de ácido cítrico por Aspergillus niger : avaliação de diferentes fontes de nitrogênio e de concentração de sacarose. Engevista, v.13, n.3, p.149-159, 2011.

PAUL, G. C.; PRIEDE, M. A.; THOMAS, C. R. Relationship between morphology and citric acid production in submerged Aspergillus niger fermentations. Biochemical Engineering Journal, n.3, p.212-129, 1999.

PENNA, T. C. V. Produção de ácidos. In: Lima, U.A., Aquarone, E., Borzani, W.,Schidell, W. Biotecnologia Industrial. São Paulo: Edgard Blucher, 2001, v.3, p. 45-50.

PINHEIRO, E. A. R.; COSTA, C. A. G.; ARAÚJO, J. C. Effective root depth of the caatinga biome. Journal of Arid Environments, v.89, p. 1-4, 2013.

RODRIGUES, C. Desenvolvimento de bioprocesso para produção de ácido cítrico por fermentação no estado sólido utilizando polpa cítrica. 2006. 107p. Dissertação (Mestrado em Processos Biotecnológicos) - Universidade Federal do Paraná. Curitiba, 2006.

ROEHR, M.; KUBICEK, C. P.; KOMINEK, J. Citric acid. Biotechnology Set, second edition, p.307-345, 1996.

SAFFRAN, M.; DENSTEDT, O. F. A rapid method for the determination of citric acid. The Journal of Biological Chemistry, v.175, p.849-855, 1948.

SANTOS, T. M. C. et al. Efeito da fertirrigação com vinhaça nos microrganismos do solo. Revista Caatinga, v.22, n.1, p.155-160, 2009.

SAUER, M. et al. Microbial production of organics acids: expanding the markets. Trends in Biotechnology, v.26, n.2, p.100-108, 2007.
SCHUSTER, E. et al. On the safety of Aspergillus niger-a review. Appl. Microbiol. Biotechnol. v.59, p.426-435, 2002.

SHU, P.; JOHNSON, M. J. The interdependence of medium constituents in citric acid production by submerged fermentation. Journal of Bacteriology, v. 56, n. 5, p. 577, 1948.

SILVA, G. K. C. et al. Utilização de resíduo agroindustrial como matéria -prima para produção de ácido cítrico por Kluveromyces marxianus URM 4404. Scientia Plena, v.8, n.5, p.1-6, 2012.

SOARES COSTA, L. M. A. et al. Citric acid production and citrate synthase genes in distinct strains of Aspergillus niger. African Journal of Biotechnology, v.13, n.22, p.2220-2226, 2014.

SOCCOL, C. R.,et al. New perpectives for citric acid production and application, Food Technol. Biotechnol., v44, n.2, p.141-149, 2006.

STEVEN, B. et al. Microbial ecology and biodiversity in permafrost. Extremophiles, v.10, n.4, p. 259-267, 2006.

THEVENIEAU, F; NICAUD, J. M. Microorganisms as sources of oils. Oilseeds \& Fats Crops and Lipids, v. 20, n. 6, p. D603, 2013.

VALENCIA, E. Y., CHAMBERGO, F. S. Mini-review: Brazialian fungi diversity for biomass degradation. Fungal Genetics and Biology, v.60, p.9-18, 2013.

VANDENBERGHE, L. P. S. et al. Microbial production of citric acid. Braz. Arch. Biol. Technol. v.42, n.3, p. 1-14, 1999.

$X U$, D. P. et al. The influence of type and concentration of carbon source on production of citric acid by Aspergillus niger. Appl. Microbiol. Biotechnol. v.30, p.553-558, 1989.

ZILLI, J.E. et al. Diversidade microbiana como indicador de qualidade do solo. Cadernos de Ciência \& Tecnologia, v.20, n.3, p.391-411, 2003.

YIGITOGLU, M. Production of citric acid by fungi. Journal of Islamic Academy of Sciences, v.5, n.2, p.100-106, 1992. 